Article

\title{
Sustainability Enhancement of a Turbine Vane Manufacturing Cell through Digital Simulation-Based Design
}

\author{
Alessandra Caggiano ${ }^{1, *}$, Adelaide Marzano ${ }^{2}$ and Roberto Teti ${ }^{3}$ \\ 1 Fraunhofer Joint Laboratory of Excellence on Advanced Production Technology (Fh-J_LEAPT Naples), \\ Department of Industrial Engineering, University of Naples Federico II, Naples 80125, Italy \\ 2 School of Mechanical and Aerospace Engineering, Queen's University Belfast, Belfast BT7 1NN, UK; \\ a.marzano@qub.ac.uk \\ 3 Fraunhofer Joint Laboratory of Excellence on Advanced Production Technology (Fh-J_LEAPT Naples), \\ Department of Chemical, Materials and Industrial Production Engineering, University of Naples Federico II, \\ Naples 80125, Italy; roberto.teti@unina.it \\ * Correspondence: alessandra.caggiano@unina.it; Tel.: +39-081-7682371; Fax: +39-081-7682362
}

Academic Editor: Hua Li

Received: 28 July 2016; Accepted: 23 September 2016; Published: 29 September 2016

\begin{abstract}
Modern manufacturing systems should satisfy emerging needs related to sustainable development. The design of sustainable manufacturing systems can be valuably supported by simulation, traditionally employed mainly for time and cost reduction. In this paper, a multi-purpose digital simulation approach is proposed to deal with sustainable manufacturing systems design through Discrete Event Simulation (DES) and 3D digital human modelling. DES models integrated with data on power consumption of the manufacturing equipment are utilized to simulate different scenarios with the aim to improve productivity as well as energy efficiency, avoiding resource and energy waste. 3D simulation based on digital human modelling is employed to assess human factors issues related to ergonomics and safety of manufacturing systems. The approach is implemented for the sustainability enhancement of a real manufacturing cell of the aerospace industry, automated by robotic deburring. Alternative scenarios are proposed and simulated, obtaining a significant improvement in terms of energy efficiency $(-87 \%)$ for the new deburring cell, and a reduction of energy consumption around $-69 \%$ for the coordinate measuring machine, with high potential annual energy cost savings and increased energy efficiency. Moreover, the simulation-based ergonomic assessment of human operator postures allows 25\% improvement of the workcell ergonomic index.
\end{abstract}

Keywords: manufacturing systems; sustainable development; simulation; discrete event simulation; 3D digital human modelling; energy management; ergonomics

\section{Introduction}

In recent years, sustainable development is claiming increasing attention worldwide as the importance of economic, social, and environmental challenges has grown significantly [1,2]. In this scenario, manufacturing can valuably contribute to global economic growth, wealth generation and job creation; however, manufacturing activities have a high impact on the environment, consuming a large amount of limited resources and producing heavy environmental pollution $(70 \%-80 \%$ of the global environmental pollution [3]). An evolution of traditional manufacturing products, processes, and systems is required to achieve new environmental objectives, such as increased resource and energy-efficiency, as well as improving occupational health and safety which are critical for sustainable development [4]. 
The enhancement of the sustainability of manufacturing systems should yield benefits related to all the three principal dimensions of sustainability: economical, environmental, and social [5-9]. These dimensions are strictly interrelated and sometimes overlapped: as an example, energy consumption, raw and supplementary material consumption, waste generation and disposal, and resource utilization can be cited as main performance indicators related to economical sustainability, but they also affect environmental sustainability. Main metrics related to environmental sustainability of manufacturing systems include emission of air pollution, amount of water used, emission of water pollution, and impact on ecosystem. Social sustainability of manufacturing systems is particularly complex and difficult to measure, including both internal and external focuses. In [10], the authors breakdown the main social sustainability criterion in four sub-criteria related to: internal human resources, external population, stakeholder participation, and macrosocial performance. With particular focus on internal human resources, sustainability concerns health and safety, employment stability, and capacity development, where a number of metrics can be defined, including accident prevention, security, usability, working conditions, and work impact on workers' welfare $[8,11]$.

Many of the aforementioned aspects related to the sustainability of manufacturing systems can be assessed and improved with the help of new digital technologies such as advanced simulation tools. In recent years, simulation has been increasingly employed in the different phases of a manufacturing system's life cycle, providing notable advantages in terms of time and cost reduction. However, environmentally related aspects are currently not available in commercial manufacturing system simulation software tools [12].

To evaluate the energy efficiency of manufacturing plants, benchmarking and auditing tools, such as the U.S. Environmental Protection Agency (EPA) Energy Performance Indicators (EPI), have been developed in recent years for specific industrial sectors (e.g., automotive industry, etc.) using annual plant energy and production data [13]. However, these tools are not able to adapt estimations to short run variations of production schedule, working shifts, operations, etc. Simulation tools would allow for more adaptive energy management strategies by predicting future energy consumption using real time feedback and optimizing energy distribution within the manufacturing plant, accordingly [14].

In the very recent literature, some approaches based on planning and optimization methods supported by simulation have been proposed to minimize energy consumption and improve energy efficiency, which are main issues in a sustainable manufacturing system [8,15-18].

In [19], the authors presented an energy oriented simulation model for planning of manufacturing systems in which the major energy flows of factories can be simulated in order to identify measures for improvement.

A hybrid simulation model, including discrete and continuous modes, was proposed in [20] to predict energy consumption and flows at both the plant and the process levels for an automotive production facility integrating sub-models based on regression analysis of historical data, forecasting, and physical modelling.

The study in [14] investigated the application of a simulation-optimization approach based on a Model Predictive Controller equipped with linear programming to optimize energy management within an automotive assembly plant. The approach was meant as a decision making support tool for planners to better control and forecast energy needs and energy mix.

In [21], a methodology was developed to represent machine power consumption in simulation models of factories with the aim of measuring the amount of total energy consumption, including non-value-added activities, which can be reduced by optimizing the production flow using dynamic simulation.

With the same scope of improving energy efficiency of manufacturing systems, in [22] a systematic approach for layout modification including an assessment of energy efficiency through discrete event simulation was proposed.

On the other hand, as concerns the improvement of human factors and ergonomics, a number of studies have been focused on the use of digital modelling and simulation tools for the analysis of 
manual operations such as assembly. In [23], the authors developed a methodology to automatically estimate the ergonomic parameters of operations in assembly cells based on simulation in a virtual environment.

In [24], a review was carried out on the use of various methodologies to develop computer-aided design systems for assembly simulation, planning and training. The authors considered that the process of virtual assembly planning should take into consideration assembly time and sequence, tooling and fixture requirements as well as operator safety and ergonomics, since the latter affects operation times and assembly reliability.

Most of the presented research studies are focused on achieving one specific objective, e.g., cost reduction, energy efficiency improvement, ergonomics assessment.

An approach for combining lean production objectives-such as setup time reduction, quality rate increase, machine availability improvement, etc.-with green strategies such as reduction of energy consumption, which are typically simulated, optimized, and validated independently, was proposed in [15].

However, sustainability of manufacturing systems should be assessed according to a holistic perspective, taking into account all three dimensions of sustainability.

The traditional life cycle assessment methods developed in the last years to quantify the environmental impact of manufacturing do not deal with other sustainability aspects such as social and economic impact [25]. To overcome these limitations, the Life Cycle Sustainability Assessment (LCSA) approach-addressing sustainability with a life cycle perspective based on interdisciplinary integration of life cycle analysis with economic models, ecological models, and social theories-has been proposed in the literature [26]. In this framework, a life cycle sustainability dashboard was presented in [27] to compare different scenarios of photovoltaic modules production through the evaluation of economic, environmental, and social sustainability indicators and the definition of an aggregated sustainability performance index.

A holistic sustainability index embedding environmental, social, economic and manufacturing variables has been also proposed in [9]. The authors integrated manufacturing indicators and analyzed the interrelationships among sustainability factors by using the analytic hierarchy process (AHP) method.

According to the holistic perspective in which the focus is widened to the economic, environmental, and human issues of sustainability, a multi-purpose digital simulation approach is proposed with the aim to deal with the diverse aspects of sustainability of manufacturing systems according to a global approach. The multi-purpose digital simulation approach is based on the incorporation of data related to energy flows and productivity into discrete event simulation (DES) models combined with ergonomics assessment through 3D digital human simulation. This methodology is validated with reference to a real manufacturing cell of the aerospace industry with the aim of enhancing the cell in the perspective of sustainability through the assessment of relevant performance indicators such as productivity, resource utilization, energy efficiency, and workcell ergonomics index. A significant improvement is obtained based on the analysis performed through the digital simulation of the manufacturing cell, providing quantitative measures of the main relevant sustainability indicators.

\section{Multi-Purpose Digital Simulation Approach}

Manufacturing systems-traditionally designed and optimized based on the requirements of cost, quality, time, and product customization — are today challenged to meet emerging needs imposed by sustainable development [3,4,7-9].

In this scenario, the aim of the proposed approach is to deal with multiple sustainability objectives in the reconfiguration of manufacturing systems. The proposed approach considers not only traditional performance indicators, such as productivity, lead time, etc., but also new indicators related to 
the sustainability of a manufacturing system, including energy efficiency, resource utilization and human factors.

The scheme of the proposed multi-purpose digital simulation approach, based on the joint employment of Discrete Event Simulation (DES) and 3D human modelling software tools, is shown in Figure 1.

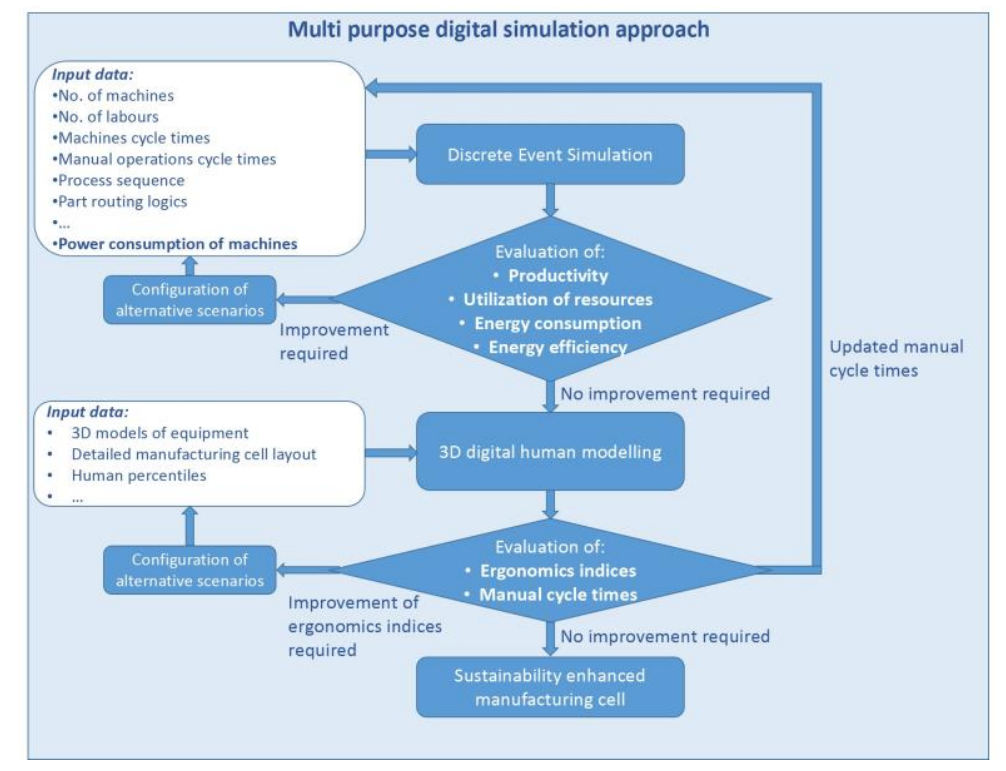

Figure 1. Scheme of the proposed multi-purpose digital simulation approach.

DES is employed to study material flow and utilization of resources (e.g., machines, equipment, robots, etc.). The information provided by DES, integrated with data on power consumption of the manufacturing system components, is utilized to assess relevant performance indicators and to configure alternative scenarios to attain optimal resource utilization and avoid energy waste. Different scenarios are set-up by modifying input variables-such as number of machines, operators, process sequence, cycle times, etc.-and simulated to increase resource utilization and reduce the idle time of critical resources to improve the energy efficiency.

Thereafter, with the aim to deal with human factors issues related to the sustainability of manufacturing systems, with specific focus on ergonomics and safety of the working environment, 3D digital simulation, based on kinematic models of humans, robots, and machines, is employed.

The starting point for the 3D digital human modelling simulation is represented by the DES simulation results, which provide the manufacturing cell configuration able to meet the desired objectives (productivity, energy efficiency, etc.). This configuration includes the required number of stations, the number of operators, the optimized process sequence, the task assignments, the processing times, the time and frequency of the part transportation tasks, etc., which represent the necessary information to carry out the 3D digital simulation on the manufacturing cell.

The 3D digital human modelling simulation, on the other hand, may lead to a modification of the manufacturing system layout to improve the ergonomics, and may be used to better estimate the cycle times of the manual operations in the improved configuration. The new output data determined via the 3D digital human modelling simulation, such as the cycle times of the manual operations after the ergonomics optimization, are fed back as input to DES with the aim to evaluate the final performance of the enhanced-sustainability manufacturing cell. In this way, the integration between the results of the two simulation approaches is carried out to complete the sustainability enhancement of the manufacturing system. 


\section{Industrial Scenario}

The multi-purpose digital simulation approach for manufacturing system sustainability enhancement is implemented with reference to a real industrial manufacturing cell dedicated to the fabrication of aircraft engine parts requiring two sequential grinding operations, geometrical inspection on a coordinate measuring machine (CMM), and final deburring.

Deburring, traditionally performed manually by high skilled operators, is a critical process that should meet close tolerances, during which minor human errors can result in severe damage to the products. A new robotic cell capable of performing automatic deburring was included in the manufacturing cell to improve process repeatability and reduce scrap rate and labor risks, key issues for sustainable development.

As shown in Figure 2a, the reconfigured manufacturing cell consists of the following components: a grinding machine tool with a loading/unloading robot; a CMM; a robotic deburring station including a robot, a deburring tools post, a rotary table for part input/output, and a touch-probe inspection device to check the part before deburring.

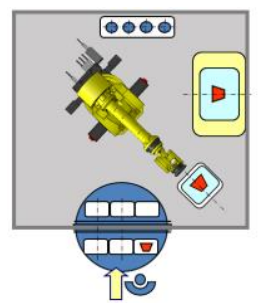

Robotic Deburring Station

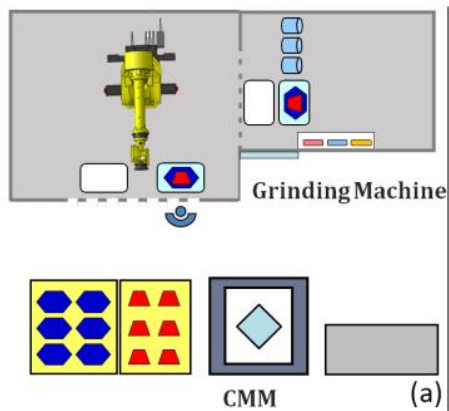

(a)

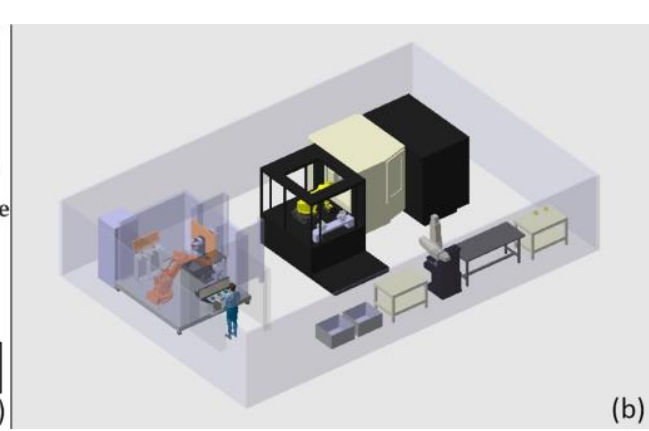

(b)

Figure 2. Manufacturing cell: (a) Schematic representation; (b) digital model.

Through the employment of digital simulation tools, the reconfiguration of the manufacturing cell can be analyzed in terms of productivity and resource utilization as well as layout configuration to verify the feasibility and the performance of the reconfigured cell [28-32]. Moreover, specific aspects relevant for the sustainability of the manufacturing cell, such as power load, energy efficiency, safety of working environment, and ergonomics, are assessed in this paper through the multi-purpose digital simulation approach based on DES and 3D simulation.

\section{DES for Resource Utilization Analysis}

DES is well known as an effective tool for manufacturing system performance analysis, which allows mapping of a set of decision variables to a set of performance measures (such as productivity level and resource utilization), to evaluate the behavior of a manufacturing system and make decisions on the appropriate strategy to adopt [33-36]. With this aim, a DES model representing the starting scenario of the reconfigured manufacturing cell was set-up (Figure $2 b$ ).

The following main assumptions were made: the grinding machine performs, alternatively, Phase 1 and Phase 2 grinding processes and no set-up time is required to switch between processes since the parts are mounted on their fixtures off the grinding machine, while the latter is still working on the previous part. The maximum availability of the grinding machine is set to $85 \%$ and the machine maintenance time is taken into account in the model. Deburring is performed at the end of the production cycle after both grinding processes. As soon as three fully ground parts are collected, they are introduced into the deburring cell through the rotary table provided with three loading positions. The deburring tools, consisting of two abrasive discs and one milling tool need to be frequently replaced due to tool wear. Accordingly, failures have been included in the model to simulate the tool change performed by the human operator (after every nine operations). Human operators work on 
three shifts of eight hours each, with breaks distributed during the day, for a total of 16 shifts per week (one shift on Saturdays and no shifts on Sundays). First-in, first-out (FIFO) logic was assigned to the buffers in the manufacturing cell, and the machines' process logic were set so that as soon as suitable input parts are available for the machine, the corresponding process is started (first possible process).

Tables and charts representing the busy and idle times of machines, robots, and laborers were generated and analyzed to assess the performance level and identify possible improvements. The results concerning the utilization of the main manufacturing cell components (CMM, grinding machine, and handling/deburring robot) show that the bottleneck of the system is the grinding machine, with the highest utilization (83\%), while the deburring robot and the CMM display a very low utilization ( $6 \%$ and $9 \%$, respectively).

To improve the sustainability of the manufacturing cell, a more comprehensive analysis is recommended to investigate the manufacturing cell energy efficiency together with the productivity indicators.

\section{DES for Energy Efficiency Estimation and Optimization}

The application to manufacturing systems of DES models integrated with the most relevant energy flows represents a promising approach to identify and digitally assess different strategies to manage energy consumption [19].

Traditional DES applications in manufacturing are aimed at improving the performance of manufacturing systems in terms of productivity, throughput time, and utilization of resources (machines, robots, operators, etc.). Different experimental scenarios can be identified, modelled, and simulated to get numerical results useful to investigate the impact produced by the variation of specified parameters on the manufacturing system performance. On the basis of the performance indicators to take into consideration, the main task is the correct modelling of the system and the identification of the most significant scenarios to investigate.

However, traditional DES applications are time or cost-driven, and do not support any consideration about the energy consumption or energy efficiency of the manufacturing system. As the latter performance indicators have become a major issue in modern manufacturing industries, due to the increase of energy prices and the recent worldwide regulations to reduce the environmental impact of manufacturing, DES modelling should be integrated by incorporating all relevant energy flows. In this way, DES tools can be employed as effective decision making support tools aimed at the achievement of energy driven objectives, beyond conventional time and cost-based targets. As a matter of fact, different performance indicators can lead to different manufacturing system configurations. A great advantage offered by DES is that it allows reproduction of the dynamic nature of production by simulating the different states of manufacturing resources, which is particularly relevant since energy related consumption and emission is not static but depends on the operation mode of the manufacturing resources. Moreover, cumulative load profiles for the whole manufacturing system may be generated during simulation as the sum of the single machine profiles.

In accordance with this new approach, DES has been employed in this paper to provide information on the distribution of power consumption during production time, allowing estimation of the consumed energy and the manufacturing cell energy efficiency (i.e., the energy required per manufactured unit) which represents one of the most relevant issues to be addressed in a sustainable manufacturing system. In order to properly feed the DES model, information on power consumption of each manufacturing cell component needs to be provided.

\subsection{Power Monitoring of the Manufacturing Cell Components}

Experimental measurements were performed on the physical manufacturing cell to gather the required data concerning power consumption of its components. Power monitoring was carried out through a Fluke 345 Power Quality Clamp Meter, calculating and recording the active power consumption values at $1 \mathrm{~Hz}$ sampling rate based on the measured values of current and voltage. 
Monitoring was performed during both the working and the idle phases of each manufacturing cell component in order to take into account the power consumption also when the component is inoperative.

For each component, the data related to active power consumption were collected and imported in MATLAB to be first visualized and then processed to extract the features of interest for the DES model, i.e., the average values of power consumption during the different states (idle, busy, etc.) of each manufacturing cell component (Figure 3a).
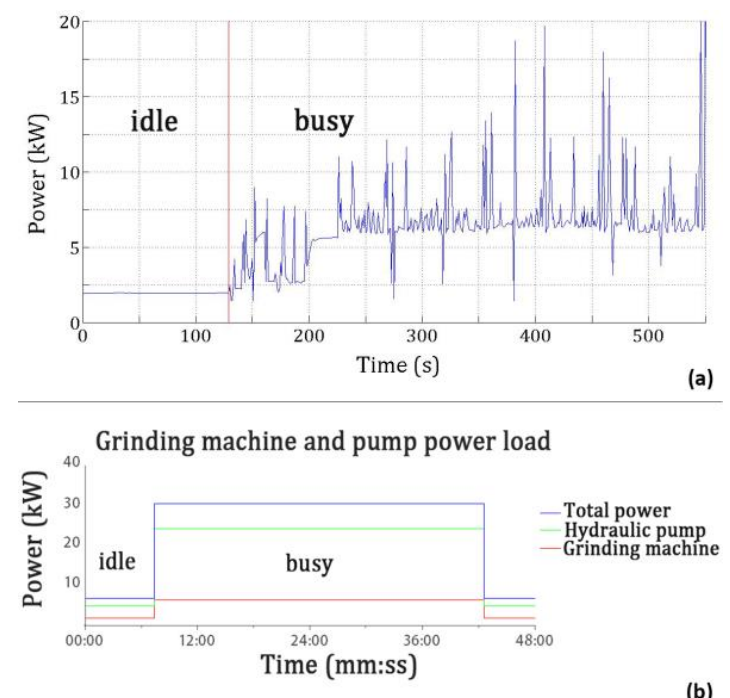

Figure 3. (a) Power consumption of the grinding machine tool under idle and busy state; (b) DES plot of power load [W] vs. time [mm:ss] for the grinding machine and the hydraulic pump during fabrication of one part.

\subsection{Distribution of Power Consumption during Production Time}

The features extracted from power monitoring data were used to model power consumption in DES. A new variable representing power demand was added in the model and related to the diverse states (e.g., busy, idle, off) of each manufacturing cell component.

The production of one batch of 34 parts was simulated with the added information on power demand to examine power consumption of the main manufacturing cell components: grinding machine, deburring station, and CMM. When applicable, the power consumption of auxiliary equipment (e.g., air compressor, hydraulic pump) was added to the power consumption of the machine itself. The simulation run, giving an estimated batch production time of about $62 \mathrm{~h}$, was able to generate plots of power load vs. time (Figure $3 \mathrm{~b}$, showing a time window of $48 \mathrm{~min}$ ) and provided the evaluation of energy consumption for the main manufacturing cell components. The energy consumption of the manufacturing cell components during the fabrication of one batch of 34 parts was equal to $1562 \mathrm{kWh}$ for the grinding machine; $37 \mathrm{kWh}$ for the CMM; and $93 \mathrm{kWh}$ for the deburring station (Table 1).

Table 1. Energy consumption of the manufacturing cell components during the fabrication of one batch of 34 parts for the different simulated scenarios.

\begin{tabular}{cccc}
\hline \multicolumn{4}{c}{ Energy Consumption (kWh) } \\
\hline Component & Scenario 1 & Scenario 2 & Scenario 3 \\
\hline Grinding machine & 1562 & 1562 & 1562 \\
CMM & 37 & 37 & 11 \\
Deburring station & 93 & 122 & 122 \\
\hline
\end{tabular}




\subsection{Energy Efficiency Improvement Strategies}

Based on the information provided by DES on machine power load during the production time of a batch, suitable strategies can be adopted to improve the manufacturing cell energy efficiency.

A first strategy to improve this index is related to the reduction of component idle times that consume energy without producing any output. As resulting from DES, the deburring robot utilization, i.e., the ratio of working time over batch throughput time, is very low (about $7 \%$ ) and the power consumption under idle state is $60 \%$ of the one in a busy state. The robot is able to perform deburring very fast but, as the grinding machine is the bottleneck of the manufacturing cell, its production capacity cannot be fully exploited.

In order to increase the deburring robot utilization, units of a different part number produced by adjacent manufacturing cells of the same industrial plant could be introduced for final deburring. This new scenario, identified as scenario 2, was modelled and simulated to investigate and quantify the resource utilization improvement. While the grinding machine processes the entire batch of the original part number units, the robotic deburring station operates on the new part number units. An average set-up time of $30 \mathrm{~min}$ to switch between the two different part numbers in the deburring station was taken into account. As soon as the entire batch of the original part number units is completely ground and measured, it is introduced in the deburring station.

The simulation run of this new scenario shows that the utilization of the deburring cell increases from $7 \%$ to $89 \%$. Moreover, its throughput is considerably increased as it includes a large amount of new part number units deburred: while the grinding machine works on one batch of the original part number units, 315 units of the new part number are deburred.

By implementing this optimized solution in the manufacturing layout, the advantages in terms of productivity would be certainly extended to the adjacent manufacturing cells, where the manual deburring process is still carried out, which could delegate most of their deburring processes to the automated deburring cell.

The overall energy consumption results are higher because the deburring station keeps working for a longer time and its busy state corresponds to a higher power demand condition (122 kWh instead of $93 \mathrm{kWh}$ in scenario 1, see Table 1). However, the energy efficiency of the deburring station, given by the ratio between energy consumption and number of deburred units, is considerably improved $(-87 \%)$ as the increase of energy demand of $29 \mathrm{kWh}(+31 \%)$ is distributed over a much larger number of products (349 units vs. 34 units).

A further strategy to reduce energy consumption is the selective activation of devices which are not working full-time. This strategy can be performed by shutting down the devices that are not required in specific periods, e.g., switching to lower energy consumption in the stand-by state [8]. In the present case, such a device should be the CMM with a utilization as low as $9 \%$. The CMM total energy consumption during idle time could be significantly reduced by turning off the compressed air supply when the machine is not operating. The power consumption of the air compressor is about $300 \%$ of the CMM electrical power consumption under idle state. The fear of lowering the reliability of measuring machines by regularly turning on and off the compressed air supply has traditionally been a concern, but new technology advancements in CMM design allow to automatically turn off the compressed air after a user-defined period without any drawback: the CMM becomes immediately operational as soon as a measuring program starts or the joystick is moved [37]. By simulating this shut down procedure in scenario 3, a reduction of CMM energy consumption around $-69 \%(11 \mathrm{kWh}$ instead of $37 \mathrm{kWh}$, see Table 1) was verified, with high potential annual energy cost saving and increased energy efficiency.

\section{Human Factors in Sustainable Manufacturing}

In the last few years, the concept of sustainability, traditionally focused on the natural environment, has been redefined including the sustainability of human resources [38]. The latter is based on long-term workability and employability, which represent key elements in ergonomics and human 
factors. Ergonomics has ancient roots in the age of ancient Egypt and the Greek and Roman period [39]; in more recent times, research studies have shown the positive effects of applying ergonomic principles to manufacturing, e.g., in workplace design [40,41]. In [42], a study was described to demonstrate how the application of ergonomic principles during product design can effectively reduce life cycle costs. Based on the concept that comfort affects productivity, different approaches have been proposed to achieve the optimal posture for workers in a manual work cell. Finding the optimal ergonomic layout of a work cell is essential to maximizing long lasting methods of operations, which benefit the worker and the time required to complete the process. Therefore, human factors and ergonomics contribute to socially sustainable development and also foster productivity and effectiveness [43].

Therefore, in view of accounting for all relevant sustainable issues related to the reconfiguration of the manufacturing cell under examination, the social dimension of the proposed evaluation was focused on the internal human resources, concerning the well-being of employees as well as the company's performance toward the ergonomic requirements fulfilment. In particular, the specific aspect of ergonomics was dealt with as this could be effectively studied through digital simulation approaches in order to achieve the ergonomic optimization of the manufacturing cell work place.

As regards the risk of worker injuries and ergonomics, it is worth mentioning that the previous manual deburring process was very labor intensive, requiring a human operator to stand and bend for a significant amount of time every day while deburring the parts. Accordingly, the introduction of the automated deburring station has drastically reduced all ergonomic risks while simultaneously reducing cycle time and enhancing quality, safety, and efficiency. Although manual processes were reduced in number due to the introduction of the automated deburring robot, many operations, such as assembly of parts and fixtures, loading and unloading of parts, still need to be carried out manually and therefore still require an accurate ergonomic analysis.

\section{Design for Ergonomics through 3D Digital Simulation}

A detailed analysis of the ergonomic aspects can be effectively supported by simulation tools, enabling the performance evaluation of human operators in a workplace before the physical system is set-up [44].

A methodology based on 3D digital human modelling was employed to simulate different scenarios of the manufacturing cell and identify the optimal layout configuration taking into account human factor issues and time savings in manual operations.

The applied methodology makes use of 3D digital human manikins that simulate human tasks in a virtual environment. The manikins have a complex kinematic linkage system that closely resembles the human skeletal structure, joints that obey the physiological range of motion restrictions, and a geometric shell that closely resembles the human shape. For the manufacturing cell under study, a range of percentiles, namely ANSUR (U.S. Army Anthropometric Survey) 50th, 95th, and 5th percentiles, and Japanese 50th percentile, were chosen from the anthropometric database of the 3D human simulation software. On these digital models, an accurate ergonomic analysis was performed by simulating the manual operations occurring within the work cell [45].

\subsection{Definition of the Ergonomics Indices}

In particular, 3D digital simulation was employed to calculate two ergonomic indices, namely the Posture Evaluation Index-PEI, and the Work Cell Evaluation Index-WEI, defined in [40], making it possible to numerically assess the ergonomic postures so that critical configurations can be identified and optimized through a proper layout reconfiguration. The Posture Evaluation Index allows us to identify whether a specific posture is deemed critical or not by integrating the results of the Low Back Compression Analysis (LBA) [46], Rapid Upper Limb Assessment (RULA) [47], and Ovako Working 
Posture Analysis System (OWAS) [48] in a synthetic adimensional index able to evaluate the "quality" of a posture, according to the equation presented in [40]:

$$
P E I=\frac{L B A}{3400}+\frac{O W A S}{3}+\frac{R U L A}{5}
$$

Once the PEI values for each operation $i$ within the manufacturing cell have been identified, the Work Cell Evaluation Index can be used to determine the optimal ergonomic configuration of the entire cell. WEI includes multiple PEI results and allows identifying the optimal configuration $J$ of a manual work cell.

For each configuration, the WEI is calculated as:

$$
\text { WEI (Configuration })=\sum_{i} P E I_{i} * W_{i}
$$

where

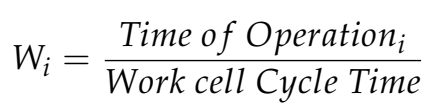

The best manufacturing cell configuration in terms of ergonomic condition is the one corresponding to the lowest WEI value, i.e.:

$$
W E I_{B E S T}=M I N_{j}\left[W E I\left(\text { Config }_{j}\right)\right]
$$

\subsection{Ergonomic Analysis of the Manual Operations in the Manufacturing Cell}

All the manual operations to be carried out by the operator in the manufacturing cell were identified and individually examined according to a design for ergonomics approach.

The first operation to be carried out by the operator is the manual assembly of turbine vanes and grinding fixtures, positioned in dedicated shelfs just outside the grinding machine. Afterwards, the handling robot picks the vane-fixture assembly and moves it to the proper position inside the grinding machine. Following grinding, the turbine vane is manually dismounted from the fixture and it is placed on the CMM for measurement. Once the vane has been measured by the CMM machine, the operator lifts the part and places it on the rotating table at the entrance of the automated deburring cell. After deburring, the finished parts are collected in an output buffer.

To identify the most critical postures, the PEI values of all the manual operations were calculated and reported in the bar chart of Figure 4.

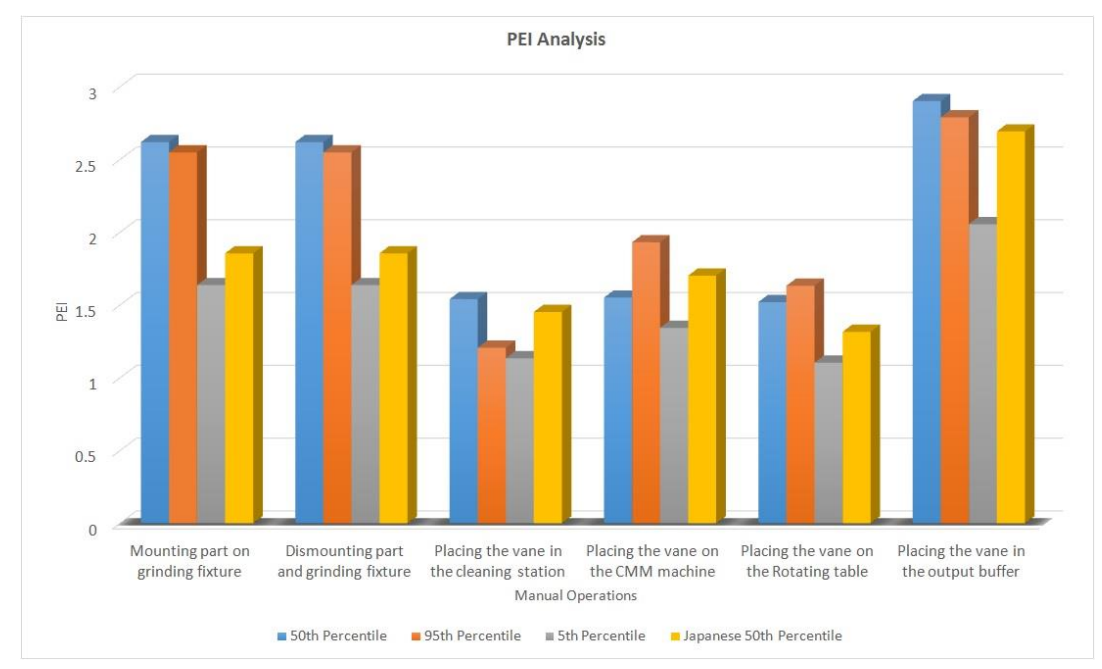

Figure 4. PEI values for the manual operations carried out in the manufacturing cell. 
The chart shows that the most dangerous operations in terms of ergonomics are mounting and dismounting of parts and fixtures as well as placing vanes in the output buffer, requiring the digital manikin to bend significantly, as shown in Figure 5. The postures required to carry out these operations are deemed critical in the tested percentiles and their repetition could lead to health and safety problems up to resulting in permanent injuries to the worker.

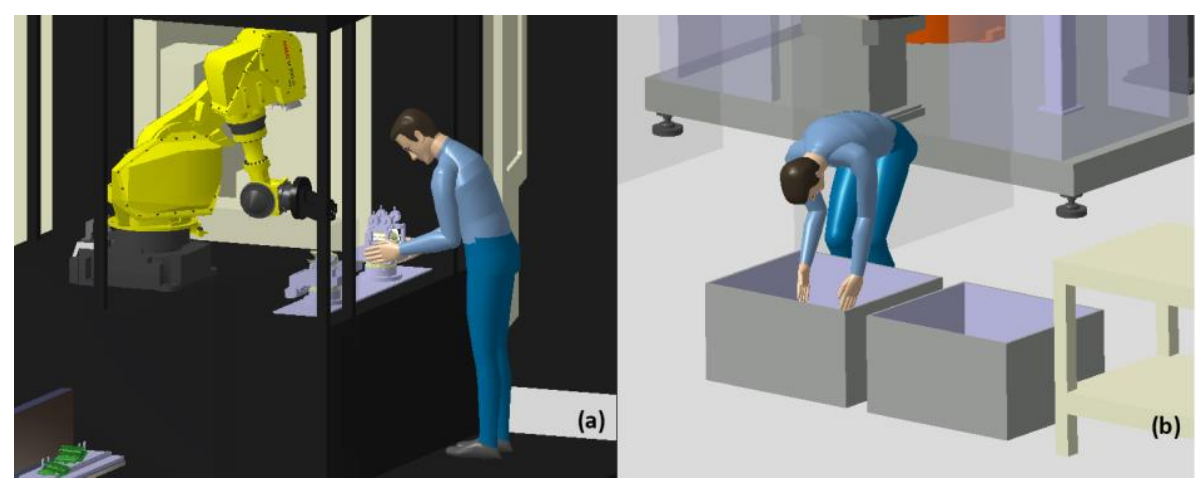

Figure 5. Postures required to perform the most critical manual operations: (a) mounting and dismounting a vane on the grinding fixture; (b) placing a vane in the Output Buffer.

With the aim to improve the overall ergonomics of the manufacturing cell, these manual operations were analyzed with particular attention to optimize and ergonomically reassess them by lowering the PEI values and improving the overall WEI value of the manufacturing cell.

\section{Optimization of the Manufacturing Cell based on Design for Ergonomics}

\subsection{PEI Analysis}

Based on the 3D digital simulation results, the operation of mounting the vanes on the grinding fixtures appeared critical due to the required postures of the operator. With the aim of improving the operator posture, an optimization process based on an incremental method was applied to identify the best location of the fixture shelf covering the needs of all percentiles. Starting from the original position, the height of the fixtures shelf was gradually increased by $5 \mathrm{~cm}$ at a time and each configuration was tested for all the human percentiles. As shown in Figure 6, lower PEI values were obtained by increasing the fixture shelf height up to $300 \mathrm{~mm}$, which was therefore selected as the best configuration. This configuration allows the operator to work in a very comfortable posture, standing with elbows at 90-degree flexion (Figure 7).

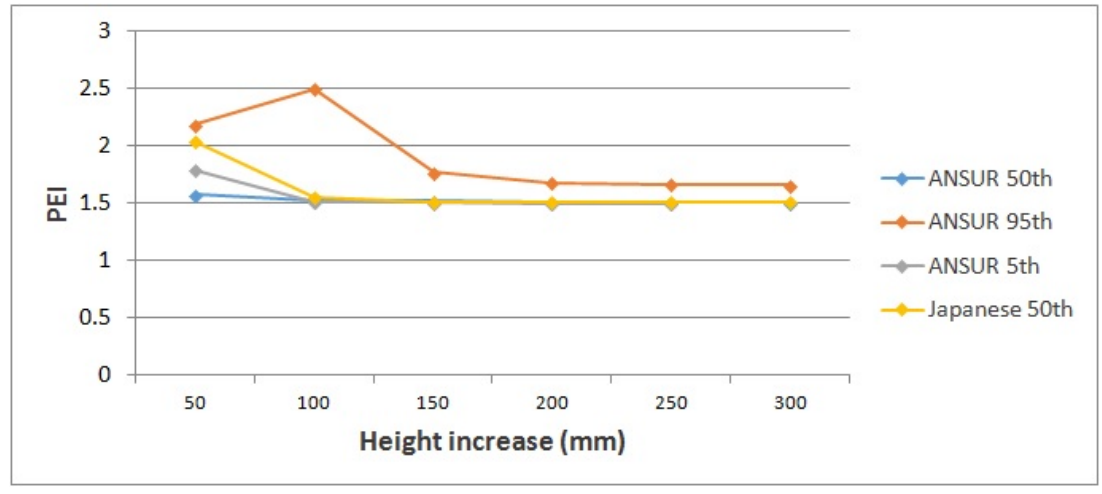

Figure 6. PEI values vs. height increase of the grinding fixture shelf. 


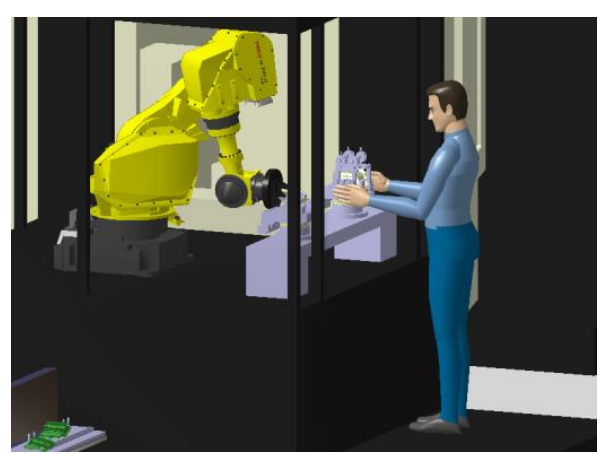

Figure 7. New fixture level configuration: the human operator stands in a more comfortable posture.

Table 2 shows the improvement of the PEI values across all percentiles obtained by optimizing the fixtures' shelf height. The most significant enhancement was achieved for the ANSUR 50th percentile, where the PEI values dropped to $42 \%$ of the starting configuration.

Table 2. PEI values resulting from the fixtures shelf level optimization and the output buffer optimization.

\begin{tabular}{|c|c|c|c|c|c|c|}
\hline \multirow{2}{*}{ Configuration } & \multirow{2}{*}{ Index } & \multicolumn{5}{|c|}{ Human Percentile } \\
\hline & & 50 & 95 & 5 & A50 & Average \\
\hline \multicolumn{7}{|c|}{ Fixtures Shelf Level Optimization } \\
\hline Old level & PEI & 2.62 & 2.55 & 2.55 & 2.30 & 2.51 \\
\hline New level & PEI & 1.51 & 1.66 & 1.51 & 1.51 & 1.54 \\
\hline \multicolumn{7}{|c|}{ Output Buffer Optimization } \\
\hline Old Box & PEI & 2.86 & 3.21 & 3.23 & 2.94 & 3.06 \\
\hline New lower shelf & PEI & 2.88 & 3.22 & 2.59 & 2.93 & 2.90 \\
\hline New middle shelf & PEI & 1.54 & 1.66 & 1.17 & 1.57 & 1.48 \\
\hline New top shelf & PEI & 2.14 & 2.17 & 2.34 & 1.81 & 2.11 \\
\hline
\end{tabular}

The second critical operation, shown in Figure $5 b$, was the positioning of vanes in the output buffer box. The 95th and 5th percentiles scored PEI values of 3.20 and 3.22 respectively, exceeding the critical limit of 3 [34], while the 50th percentile scored a PEI value of 2.90. Moreover, the repetitiveness of this task over time could have a negative impact on the work force.

Therefore, to fulfil the ergonomic requirements of the operation posture, an alternative output buffer consisting of a multi-level rack of shelves was proposed and assessed. The multiple levels allow workers to carry out the tasks more comfortably and can be accessed from both sides, saving time and effort.

3D digital human simulation was used to obtain the LBA, OWAS, and RULA indices in order to calculate a PEI value for each rack level posture (Figure 8).

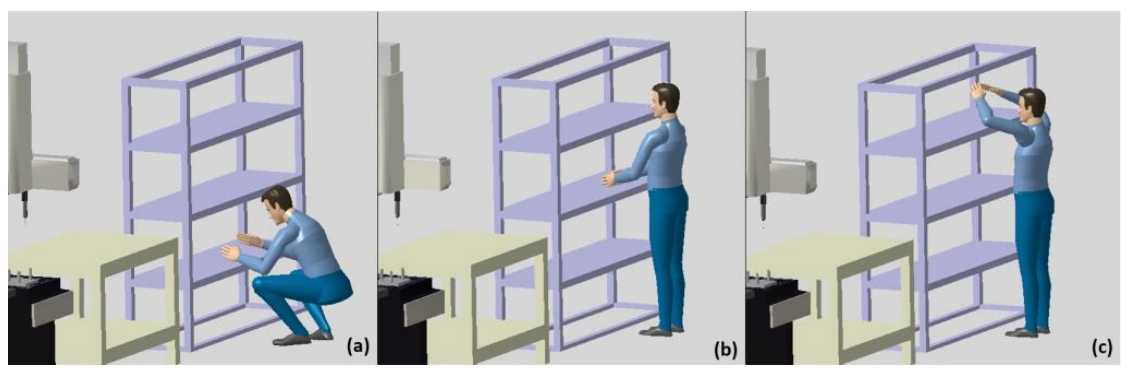

Figure 8. Analysis of postures for reaching the rack shelves: (a) bottom; (b) middle; (c) top. 
The height of the middle shelf resulted to be the most comfortable for the human operator, as shown in Table 1 summarizing the average PEI value across all percentiles.

The PEI values were significantly reduced in comparison with the initial output buffer configuration, with a reduction of $52 \%$ in the case of the middle shelf.

With the aim to estimate the time saving achieved by improving the postures assumed by the operators, time analysis was performed on the optimized manufacturing cell by means of 3D digital human modelling. In the case of mounting and dismounting of vanes on the grinding fixtures, no major time variation was observed in the new configuration, whereas a 33\% time reduction after optimization was achieved for the manual task of positioning of vanes in the output buffer. Therefore, this new configuration provides advantages to the manufacturing company both in terms of ergonomics and time.

\subsection{WEI Analysis}

The main objective in terms of ergonomic improvement was to obtain a lower WEI value for the manufacturing cell. Based on the PEI values of each operation and the corresponding estimated operation time, the WEI values for each percentile were calculated for the manufacturing cell before and after the posture optimization. The values for the different percentiles are shown in Figure 9.

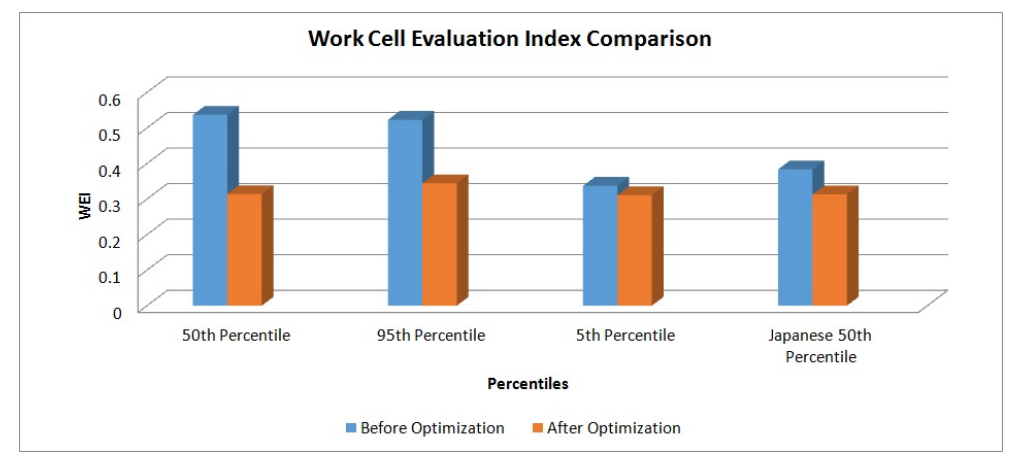

Figure 9. WEI comparison before and after optimization.

The figure shows that, by changing the posture of two manual operations, the WEI value of the whole manufacturing cell significantly dropped across all percentiles. In particular, the main improvement was obtained for the 50th percentile that achieved a WEI reduction of $41 \%$. Moreover, it is worth noting that the optimized manufacturing cell is characterized by more homogeneous WEI values across the percentiles, which means that the new configuration is more suitable to meet the different needs.

An overall WEI reduction of $25 \%$ has several positive implications for the work cell. A more ergonomically friendly work cell reduces the chances of stress or strain related injuries for workers over time and helps improve their productivity and working endurance. Moreover, the safety of the work cell as a whole increases, making work related accidents less likely to occur.

\section{Conclusions and Outlook}

A multi-purpose digital simulation approach was proposed with particular attention to sustainability issues from the economic, environmental, and human factors viewpoints. The approach was validated with reference to a real industrial manufacturing cell of the aerospace field. DES integrated with power demand enabled the envisaging and digital experiment strategies to improve energy efficiency and optimize the exploitation of available resources during the design stage.

Different alternative scenarios were proposed and the results showed that a significant improvement in terms of energy efficiency $(-87 \%)$ was achieved for the new automated deburring 
cell, and a reduction of the CMM energy consumption around $-69 \%$ was verified with high potential annual energy cost saving and increased energy efficiency.

Finally, with the aim of improving the human factors related sustainability of the manufacturing cell, ergonomics analysis carried out by means of 3D digital human simulation allowed verification of the suitability of the designed layout for the well-being of human operators. The manual operations in the manufacturing cell were examined and two main ergonomic indices, the Posture Evaluation Index (PEI) and the Work Cell Evaluation Index (WEI), were estimated. To enhance the ergonomics of the manufacturing cell, a methodology was applied to improve the comfort of the human workers during manual operations and changes to the layout of the cell were proposed. The new postures were ergonomically assessed and an overall WEI reduction of $25 \%$ was achieved across all the considered human percentiles.

Further research work will focus on the integration of data concerning costs related to materials and energy flows into the simulation model to allow for the economic assessment of the different alternatives. Moreover, future developments will involve the joint use of digital simulation and suitable optimization tools to effectively support the search for the optimal system configuration in a broader solution space.

Acknowledgments: The Fraunhofer Joint Laboratory of Excellence for Advanced Production Technology (Fh-J_LEAPT) at the Department of Chemical, Materials, and Industrial Production Engineering, University of Naples Federico II, and the School of Mechanical and Aerospace Engineering, Queen's University Belfast, are gratefully acknowledged for their contribution and support to this research activity. Acknowledgements are also due to the "ADAPTIVE MANUFACTURING" project on "Modular and Adaptive Approach for the Digital Factory" (CTN01_00163_216730) of the Italian National Technology Cluster on Intelligent Factory.

Author Contributions: All authors contributed substantially to the study reported. Alessandra Caggiano and Adelaide Marzano conceived and designed the presented approach, performed the simulations, and analyzed the data; Roberto Teti contributed to the discussions and outlook of the results, providing important comments on the modelling and analysis.

Conflicts of Interest: The authors declare no conflict of interest.

\section{References}

1. Jovane, F.; Yoshikawa, H.; Alting, L.; Boër, C.R.; Westkamper, E.; Williams, D.; Tseng, M.; Seliger, G.; Paci, A.M. The incoming global technological and industrial revolution towards competitive sustainable manufacturing. CIRP Ann. 2008, 57, 641-659. [CrossRef]

2. Westkämper, E. Life cycle management and assessment: Approaches and visions towards sustainable manufacturing. CIRP Ann. 2000, 49, 501-526. [CrossRef]

3. Jayal, A.D.; Badurdeen, F.O.; Dillon, W.J.; Jawahir, I.S. Sustainable manufacturing: Modeling and optimization challenges at the product, process and system levels. CIRP J. Manuf. Sci. Technol. 2010, 2, 144-152. [CrossRef]

4. United Nations. Sustainable Development Goals. Available online: http://www.un.org/sustainable development/infrastructure-industrialization/ (accessed on 30 August 2016).

5. Westkämper, E.; Constantinescu, C.; Hummel, V. New paradigms in Manufacturing Engineering: Factory Life Cycle. Ann. Academic Society Prod. Eng. Res. Dev. 2006, 8, 143-147.

6. 2005 United Nations World Summit Outcome. Available online: http://www.cfr.org/internationalorganizations-and-alliances/un-world-summit-outcome-2005/p22092 (accessed on 30 August 2016).

7. Chen, D.; Heyer, S.; Seliger, G.; Kjellberg, T. Integrating sustainability within the factory planning process. CIRP Ann. 2012, 61, 463-466. [CrossRef]

8. Duflou, J.R.; Sutherland, J.W.; Dornfeld, D.; Herrmann, C.; Jeswiet, J.; Kara, S.; Hauschild, M.; Kellens, K. Towards energy and resource efficient manufacturing: A processes and systems approach. CIRP Ann. 2012, 61, 587-609. [CrossRef]

9. Harik, R.; EL Hachem, W.; Medini, K.; Bernard, A. Towards a holistic sustainability index for measuring sustainability of manufacturing companies. Int. J. Prod. Res. 2015, 53, 4117-4139. [CrossRef]

10. Labuschagne, C.; Brent, A.C.; van Erck, R.P.G. Assessing the sustainability performances of industries. J. Clean. Prod. 2005, 13, 373-385. [CrossRef] 
11. Tan, X.C.; Wang, Y.Y.; Gu, B.H.; Mu, Z.K.; Yang, C. Improved Methods for Production Manufacturing Processes in Environmentally Benign Manufacturing. Energies 2011, 4, 1391-1409. [CrossRef]

12. Thiede, S.; Seow, Y.; Andersson, J.; Johansson, B. Environmental aspects in manufacturing system modelling and simulation-State of the art and research perspectives. CIRP J. Manuf. Sci. Technol. 2012, 6, 78-87. [CrossRef]

13. Energy Star Energy Performance Indicators for Plants. Available online: https://www.energystar.gov/ buildings/facility-owners-and-managers/industrial-plants/measure-track-and-benchmark/energy-starenergy (accessed on 30 August 2016).

14. Zhu, Q.; Lujia, F.; Mayyas, A.; Omar, M.A.; Al-Hammadi, Y.; Al Saleh, S. Production energy optimization using low dynamic programming, a decision support tool for sustainable manufacturing. J. Clean. Prod. 2015, 105, 178-183. [CrossRef]

15. Diaz-Elsayed, N.; Jondral, A.; Greinacher, S.; Dornfeld, D.; Lanza, G. Assessment of lean and green strategies by simulation of manufacturing systems in discrete production environments. CIRP Ann. 2013, 62, 475-478. [CrossRef]

16. Seow, Y.; Rahimifard, S.; Woolley, E. Simulation of energy consumption in the manufacture of a product. Int. J. Comp. Integr. Manuf. 2013, 26, 663-680. [CrossRef]

17. Choi, Y.C.; Xirouchakis, P. A holistic production planning approach in a reconfigurable manufacturing system with energy consumption and environmental effects. Int. J. Comp. Integr. Manuf. 2015, 28, 379-394. [CrossRef]

18. Solding, P.; Petku, D.; Mardan, N. Using Simulation for More Sustainable Production Systems-Methodologies and Case Studies. Int. J. Sustain. Eng. 2009, 2, 111-122. [CrossRef]

19. Herrmann, C.; Thiede, S.; Kara, S.; Hesselbach, J. Energy oriented simulation of manufacturing systems-Concept and application. CIRP Ann. 2011, 60, 45-48. [CrossRef]

20. Omar, M.A.; Zhou, Q.; Lujia, F.; Abou Ali, A.; Lahjouji, D.; Khraisheh, M. A hybrid simulation approach for predicting energy flows in production lines. Int. J. Sustain. Eng. 2016, 9, 25-34. [CrossRef]

21. Johansson, B.; Skoogh, A.; Andersson, J.; Ahlberg, K.; Hanson, L. Power-level sampling of metal cutting machines for data representation in discrete event simulation. Int. J. Prod. Res. 2015, 53, 7060-7070. [CrossRef]

22. De Oliveria Gomes, V.E.; de Oliveria Gomes, J.; Grote, K.H. Discrete Event Simulation Inserted into Kaizen Event to Assess Energy Efficiency. In Re-Engineering Manufacturing for Sustainability; Nee, A.Y.C., Song, B., Ong, S.K., Eds.; Springer: Singapore, Singapore, 2013.

23. Enomoto, A.; Yamamoto, N.; Suzuki, T. Automatic Estimation of the Ergonomics Parameters of Assembly Operations. CIRP Ann. 2013, 62, 13-16. [CrossRef]

24. Leu, M.C.; ElMaraghy, H.A.; Nee, A.Y.; Ong, S.K.; Lanzetta, M.; Putz, M.; Zhu, W.; Bernard, A. CAD model based virtual assembly simulation, planning and training. CIRP Ann. 2013, 62, 799-822. [CrossRef]

25. Mayyas, A.; Qattawi, A.; Omar, M.A.; Dongri, S. Design for sustainability in automotive manufacturing: A comprehensive review. Renew. Sustain. Energy Rev. 2012, 16, 1845-1862. [CrossRef]

26. Zamagni, A. Life cycle sustainability assessment. Int. J. Life Cycle Assess. 2012, 17, 373-376. [CrossRef]

27. Traverso, M.; Asdrubali, F.; Francia, A.; Finkbeiner, M. Towards life cycle sustainability assessment: An implementation to photovoltaic modules. Int. J. Life Cycle Assess. 2012, 17, 1068-1079. [CrossRef]

28. Caggiano, A.; Teti, R. Digital Factory Simulation Tools for the Analysis of a Robotic Manufacturing Cell. In Proceedings of the 7th International Conference on Digital Enterprise Technology, Athens, Greece, 28-30 September 2011; pp. 478-485.

29. Caggiano, A.; Teti, R. Digital manufacturing cell design for performance increase. Procedia CIRP 2012, 2, 64-69. [CrossRef]

30. Caggiano, A.; Teti, R. Modelling, analysis and improvement of mass and small batch production through advanced simulation tools. Procedia CIRP 2012, 12, 426-431. [CrossRef]

31. Caggiano, A.; Caiazzo, F.; Teti, R. Digital Factory Approach for Flexible and Efficient Manufacturing Systems in the Aerospace Industry. Procedia CIRP 2015, 37, 122-127. [CrossRef]

32. Caggiano, A.; Marzano, A.; Teti, R. Resource Efficient Configuration of an Aircraft Assembly Line. Procedia CIRP 2016, 41, 236-241. [CrossRef]

33. Banks, J.; Carson, J.S.; Nelson, B.L.; Nicol, D.M. Discrete-Event System Simulation. Technometrics 1984, 26, 195-195. 
34. Hosseinpour, F.; Hajihosseini, H. Importance of simulation in manufacturing. World Acad. Sci. Eng. Technol. 2009, 51, 285-288.

35. Mourtzis, D.; Doukas, M.; Bernidaki, D. Simulation in Manufacturing: Review and Challenges. Procedia CIRP 2014, 25, 213-229. [CrossRef]

36. Negahban, A.; Smith, J.S. Simulation for manufacturing system design and operation: Literature review and analysis. J. Manuf. Syst. 2014, 33, 241-261. [CrossRef]

37. Carl, Z. Industrielle Messtechnik GmbH Innovation Reduces Compressed Air Consumption. Innov. Metrology Special 2013, 16, 48-49.

38. Steimle, U.; Zink, K.J. Sustainable development and human factors. In International Encyclopedia. of Ergonomics and Human Factors, 2nd ed.; Karwowski, W., Ed.; Taylor \& Francis: London, UK, 2006; pp. 2355-2360.

39. Marmaras, N.; Poulakakis, G.; Papakostopoulos, V. Ergonomic design in ancient Greece. Appl. Ergon. 1999, 30, 361-368. [CrossRef]

40. Di Gironimo, G.; Di Martino, C.; Lanzotti, A.; Marzano, A.; Russo, G. Improving MTM-UAS to predetermine automotive maintenance times. Int. J. Interact. Des. Manuf. 2012, 6, 265-273. [CrossRef]

41. McKay, A.; Stiny, G.N.; de Pennington, A. Principles for the definition of design structures. Int. J. Comp. Integr. Manuf. 2015, 29, 237-250. [CrossRef]

42. Curran, R.; Gomis, G.; Castagne, S.; Butterfield, J.; Edgar, T.; Higgins, C.; McKeever, C. Integrated digital design for manufacture for reduced life cycle cost. Int. J. Prod. Econ. 2007, 109, 27-40. [CrossRef]

43. Wang, C.G.; Mitrouchev, P.; Li, G.Q.; Lu, L.X. Disassembly operations' efficiency evaluation in a virtual environment. Int. J. Comp. Integr. Manuf. 2015, 29, 309-322. [CrossRef]

44. Joung, Y.K.; Li, Q.; Noh, S.D. XML-based neutral schema for automated ergonomic analysis with digital human simulation and inline motion capture. Int. J. Comp. Integr. Manuf. 2014, 29, 25-41. [CrossRef]

45. Caputo, F.; Di Gironimo, G.; Marzano, A. Ergonomic optimization of a manufacturing system work cell in a virtual environment. Acta Polytechnica 2006, 46, 21-27.

46. Dempsey, P.G. Usability of the revised NIOSH lifting equation. Ergonomics 2002, 45, 817-828. [CrossRef] [PubMed]

47. McAtamney, L.; Corlett, E.N. RULA: A survey method for the investigation of work-related upper limb disorders. Appl. Ergon. 1993, 24, 91-99. [CrossRef]

48. Keyserling, W.; Brouwer, M.; Silverstein, B. A checklist for evaluating ergonomic risk factors resulting from awkward postures of the legs, trunk and neck. Int. J. Ind. Ergon. 1992, 9, 283-301. [CrossRef] 